\title{
Experience for Coal Mine Methane Utilization to Generate Thermal and Electric Power
}

\author{
TAILAKOV Oleg V., ZASTRELOV Denis. N., UTKAEV Evgeniy A., \\ SMYSLOV Alexey I., KORMIN Alexey N.
}

\section{Institute of Coal SB RAS 650000 Kemerovo, Russia}

\begin{abstract}
Here an experience on utilization of coal mine methane (CMM) to generate thermal and electric power at Kuzbass coal mines is given. A process model of CMM utilization is presented in the form of a Petri net.
\end{abstract}

Keywords: coal mine methane, thermal power, electric power, power generating plant.

\section{Introduction}

Nowadays, the majority coal mines of Russian mainly release methane into the atmosphere and almost never utilize it. Whereas, the extracted coal mine methane (CMM) can be processed for generation of thermal and electric power, which can be used by coal companies for own needs and/or delivered to an outside customers ${ }^{[1]}$.

\section{Work description}

Nevertheless, several projects on CMM utilization were fulfilled in Kuzbass. Mine 'Krasnogorskaya' in Prokopyevsk introduced modular boiler of $0.7 \mathrm{MW}$ capacity for thermal power generation (Fig. 1). The equipment allows using airmethane mixture with a methane concentration not lower $25 \%$.

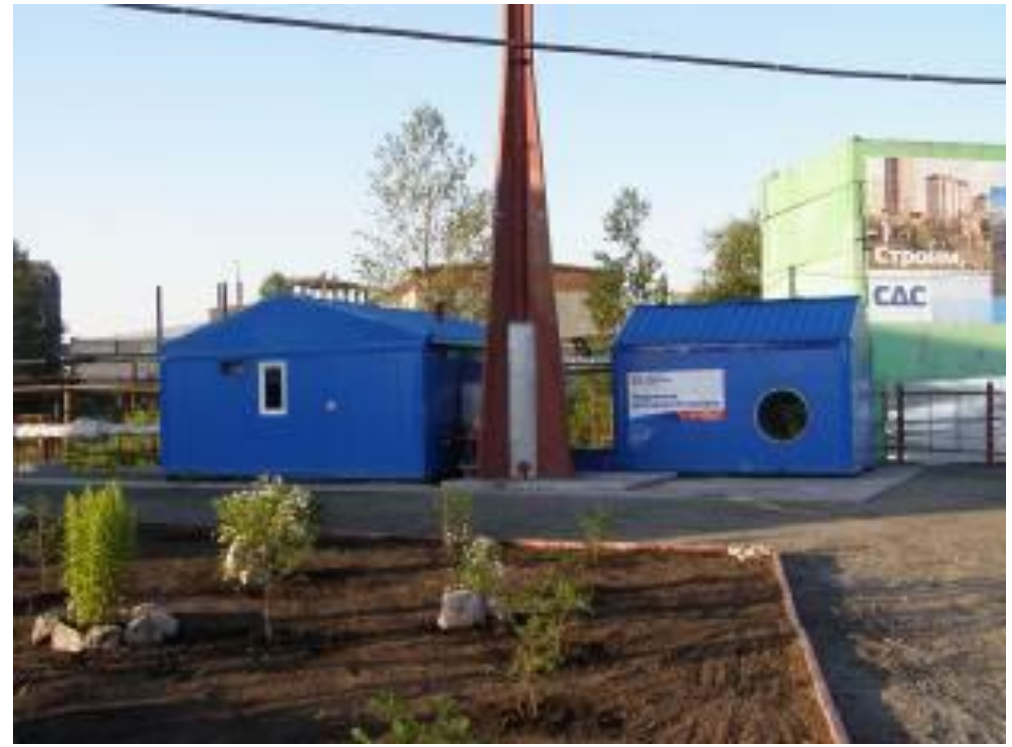

Fig. 1: Modular Boiler at 'Krasnogorskaya' mine

At the mine gas generating plant of 0.9 MW capacity for electric power generation was put into operation. For sufficient work of the generator the concentration of methane in air methane should be not lower $35 \%$. This plant has 
been operating at the mine since $2009 \quad$ (Fig. 2).

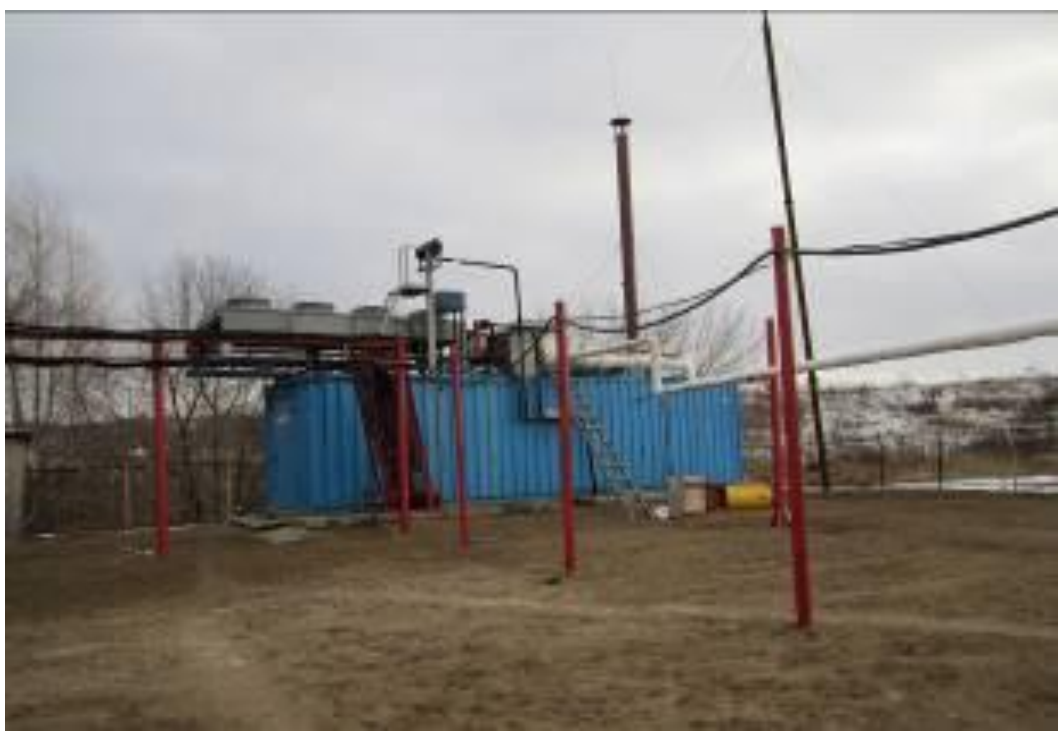

Fig. 2: Gas Generating Plant at 'S.M. Kirov' mine

In 2012 'Komsomolets' mine two sources of air-methane: low (less implemented a project for methane than 3.5\%) and high (over 25\%) utilization by generation unit with the set concentration of methane was electrical capacity of 0.4 MW (Fig. 3). successfully tested.

The technology of simultaneously use of

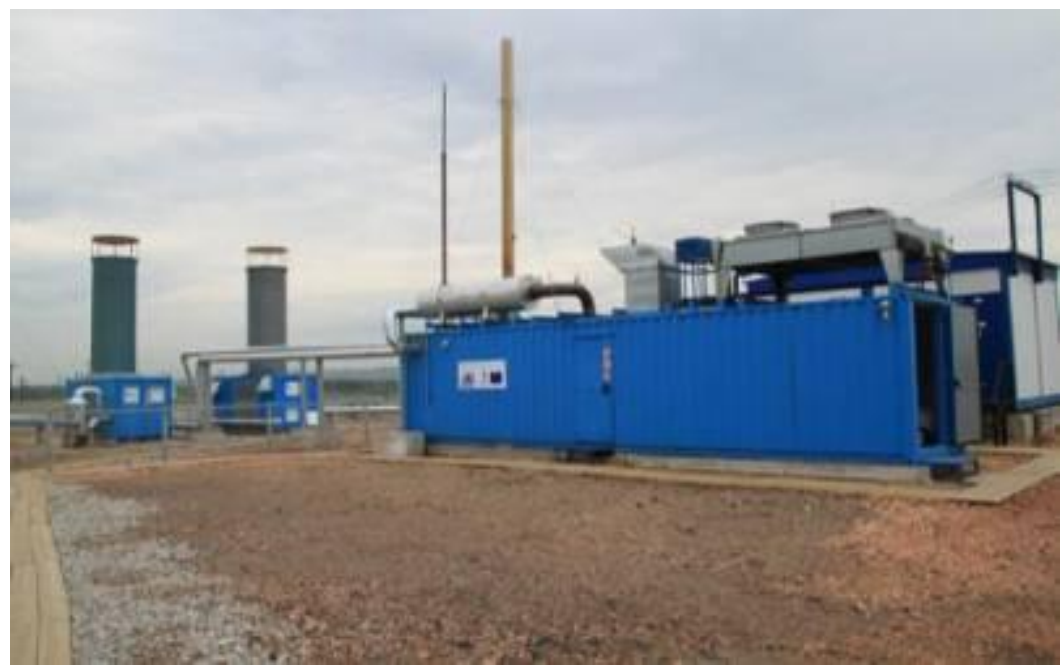

Fig. 3: Generating station at 'Komsomolets' mine

Enhancement of degassing systems efficiency, introduction of modern methods of methane extraction ${ }^{[2]}$ would improve the volume of the extracted air methane. One of the possible intensification methods for methane production is pumping of carbon dioxide into coal seams to release methane ${ }^{[3]}$.

Due to gradual development of CMM utilization projects at the coal mines, the issue of assessment of the efficiency of power plants and reducing possible 
downtime is very urgent. To evaluate the performance of CMM utilization projects it is possible to use directed graphs, which will display the structure of the investigated systems, technological process of CMM utilization, and economic models to describe their main economic data for CMM utilization projects.

The process model of CMM utilization is presented in the form of a Petri net $N=$ $\left\{\boldsymbol{P}, \boldsymbol{T}, \boldsymbol{I}, \boldsymbol{O}, \boldsymbol{M}_{\boldsymbol{0}}\right\}$, which consists of a finite set of positions $\boldsymbol{P}=\left\{\boldsymbol{p}_{1}, \boldsymbol{p}_{2}, \ldots, \boldsymbol{p}_{\boldsymbol{m}}\right\}$, corresponding to the main technological units, final set of transitions $T=\left\{t_{1}, t_{2}, \ldots\right.$, $\boldsymbol{t}_{\boldsymbol{n}} \boldsymbol{\}}$, characterizing the process of the thermal power generation, connected by arcs: $\boldsymbol{I}$ - input function, $\boldsymbol{O}$ - output function, which reflects the equipment work, and also has primary marking $\boldsymbol{M}_{\boldsymbol{\theta}}$, which corresponds ventilation air methane and thermal power at the initial stage of work of the modular boiler. Operation of the network $\boldsymbol{N}$ is carried out by means of switching transitions. Through the use of mathematical Petri net, a directed graph $\mathrm{N}_{1}$ (Fig. 4) was built.

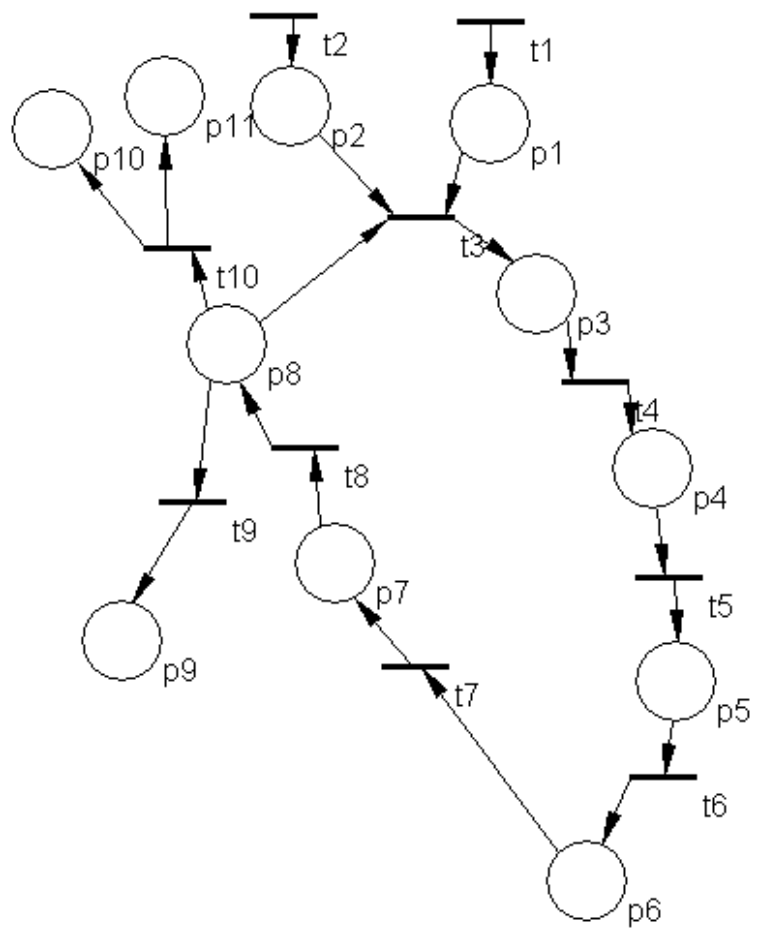

Fig. 4: Network $N_{l}$, reflecting the utilization process of CMM in the modular boiler

The methane utilization process is characterized as follows: Air methane is extracted by vacuum pumping unit $\boldsymbol{p}_{3}$, then it is fed to the condensate collector number $1 \boldsymbol{p}_{4}$ for cleaning from dust and moisture, then to the condensate collector number $2 p_{5}$ for further purification and then to the gas pressure controller $\boldsymbol{p}_{6}$, which smooth out pressure kick in a pipeline. Free of dust and moisture air methane is fed to a gas burner $\boldsymbol{p}_{7}$, where methane is mixed with air to achieve the required quality. On the next stage the gas mixture is fed into the furnace $\boldsymbol{p}_{8}$, where methane is combusted generating thermal power. Part of the thermal energy is used for own needs of the boiler, the remaining energy is fed into the shower facilities of the mine $\boldsymbol{p}_{\mathbf{1 0}}$. (Table 1) 
Table 1: Interpretation of items $\boldsymbol{P}$ and transitions $\boldsymbol{T}$ net $\boldsymbol{N}_{\boldsymbol{I}}$

\begin{tabular}{|c|c|}
\hline Позиции $\boldsymbol{P}$ & Переходы $\boldsymbol{T}$ \\
\hline $\begin{array}{l}p_{1}-\text { gas pipeline; } \\
p_{2}-\text { switchboard; } \\
p_{3}-\text { vacuum pump unit; } \\
\boldsymbol{p}_{4}-\text { condensate collector №1; } \\
\boldsymbol{p}_{5}-\text { condensate collector №2; } \\
\boldsymbol{p}_{6}-\text { gas pressure control; } \\
\boldsymbol{p}_{7}-\text { burner; } \\
\boldsymbol{p}_{8}-\text { furnace; } \\
\boldsymbol{p}_{9}-\text { chimney; } \\
\boldsymbol{p}_{10}-\text { system of heat consumption; } \\
\boldsymbol{p}_{11}-\text { meter. }\end{array}$ & $\begin{array}{l}t_{1}-\text { methane production; } \\
t_{2} \text { - electricity to a switchboard; } \\
t_{3} \text { - methane to vacuum-pumping station; } \\
t_{4}-\text { methane feeding; } \\
t_{5} \text { - methane cleaning; } \\
t_{6} \text { - further purification of methane; } \\
t_{7} \text { - smoothing out pressure kick in pipeline; } \\
t_{8} \text { - mixing methane and air; } \\
t_{9} \text { - feeding of exhausted air to chimney; } \\
t_{10} \text { - thermal power to thermal consumer grid. }\end{array}$ \\
\hline
\end{tabular}

\section{Conclusions}

The designed directed graph of CMM utilization process in modular boiler for generation of thermal power conducts numerical experiments and performs assessment of the properties of the network model. The simulation results can be used to adjust the technological modes of modular boiler to improve the efficiency and sustainability of the equipment.

Introduction of the energy efficient technologies based on CMM utilization allows efficient use of valuable energy resources to generate, for example, thermal and electric power. Successful examples of such projects in Kuzbass allow further development utilization of coal mine methane.

\section{References}

[1] Backhaus C., Bezpflyug V.A., Mazanik EV, Hoppe C. Experience of implementing mobile Thermal Power Plants on CMM // Coal. - 2009. - № 11 50-53p.

[2] Polevshikov G.Y., Kozyreva E.N., Shankevich M.V. Enhancement of efficiency of the integrated degassing management at coal face operations // Bulletin of the science center on safety in coal industry. Scientific and Technical Journal, Kemerovo, 2012. - № 2. - 20-27p. [3] Tailakov O.V., Zastrelov D.N., Tailakov V.O., Kormin A.N. Capture and storage of carbon dioxide at Kuzbass coal seams // Gas Industry № 12/699/2013, Moscow: Publishing House 'Gasoil press' 2013. - 86-87p. 